\title{
Historia, biografía, encomio y exemplum en los Rerum memorandarum libri de Francesco Petrarca
}

\author{
Alejo Perino ${ }^{1}$
}

Resumen. El presente artículo pretende analizar la producción historiográfica de Francesco Petrarca, con especial atención a los Rerum memorandarum libri. Uno de los objetivos es caracterizar el género historiográfico del texto a partir de su modelo, los Factorum et dictorum memorabilium libri, de Valerio Máximo. Se podrá observar que Petrarca utiliza este género con el fin de exponer un ideal de vida entre el otium y el negotium, como también hace en otros textos. Veremos que en este texto en particular ese ideal se manifiesta en el uso del exemplum, pero a su vez encuentra su límite en el modelo heroico de la biografía. En este sentido, el análisis del encomio que el autor realiza al rey Roberto de Anjou dará cuenta de esa tensión.

Palabras clave: Petrarca; Rerum memorandarum libri; biografía; exemplum; encomio.

\section{[en] History, biography, praise and exemplum in Petrarch's Rerum memorandarum libri}

Summary. The present paper intends to analyze Francesco Petrarch's historical production, with a special focus on the Rerum memorandarum libri. One of the main aims of the research is to characterize the historical genre of the text, taking as model Valero Máximo's Factorum et dictorum memorabilium libri. It is possible to observe that Petrarch uses this genre with the final purpose of exposing an ideal of life between the otium and the negotium, as he makes in other texts. In addition, it can also be observed in this particular text that the medium ideal is manifested in the use of exemplum, but this ideal is limited by the heroic model of the biography. In this sense, this tension will be realised in the analysis of the way in which the author prasises the King Roberto de Anjou.

Key words: Petrarch; Rerum memorandarum libri; biography; exemplum; praise.

Sumario: 1. La concepción historiográfica de Petrarca 2. Valerio Máximo y los Rerum memorandarum libri 3. El De vita solitaria 4. El equilibrio entre otium y negotium 5. El elogio a Roberto de Anjou 6. Los Rerum memorandarum libri en la producción del autor 7. Conclusiones.

Cómo citar: Perino, Alejo (2020): «Historia, biografía, encomio y exemplum en los Rerum memorandarum libri de Francesco Petrarca», Cuadernos de Filología Italiana, 27, pp. 167-182.

1 Universidad de Buenos Aires, Facultad de Filosofía y Letras, Departamento de Letras, Puán 480.

E-mail: aleperino@hotmail.com 


\section{La concepción historiográfica de Petrarca}

El interés de Petrarca por la Historia se evidencia en muchas de sus obras. En su carta a la posteridad, luego de definir su inclinación por la poesía y la filosofía moral, menciona que su deseo de escapar de su propio tiempo lo llevó también al estudio de la Historia. Dice allí también que le gustaba leer a los historiadores, pero no le gustaban sus discordias ${ }^{2}$. Es fácil saber de qué historiadores habla porque el mismo autor nos ha dejado una lista de auctores peculiares, que compiló entre los años 1330-40, en el Par. Lat. 2201. En la sección de historiadores aparecen Valerio Máximo, Tito Livio, Justino, Floro, Salustio, Suetonio, Festo y Eutropio (Ullman 1923)

A pesar de haber dedicado gran parte de su vida al estudio de los antiguos, suele afirmarse habitualmente en los estudios sobre el Renacimiento que la historiografía humanista comienza con Leonardo Bruni y Flavio Biondo (Wilcox 1969). La mayoría de los investigadores considera los textos históricos de Petrarca como un antecedente más relacionado con los modelos medievales que con los humanistas del Quattrocento ${ }^{3}$. Sin embargo, estudios recientes consideran que el principal rasgo que define la concepción historiográfica a la que adhiere Petrarca continuó vigente a lo largo de todo el Renacimiento. Ello es así porque la Historia fue concebida por los humanistas en general como parte de la Retórica. Esa concepción, heredada de la Retórica clásica, supone que el principal objetivo del historiador es inspirar en la audiencia amor por la virtud y rechazo por los vicios. ${ }^{4}$

«Historicis itaque delectatus sum, non minus tamen offensus eorum discordia» 'Me gustaban por ello los historiadores, aunque me disgustaran sus discrepancias' (Petrarca 2011: 484). Todas las traducciones son nuestras.

Hay muchas razones para afirmarlo. En primer lugar, Petrarca no sabía griego y desconocía la obra de Plutarco, aunque conocía su nombre a través del Policraticus de John de Salisbury, en el que se comenta la Institutio Traiani, la supuesta epístola de Plutarco a Trajano. Además, sabía de la existencia de las Vidas paralelas, ya que en la Epístola a Séneca afirma que Plutarco comparó a griegos y romanos. La primera traducción al latín de un texto de Plutarco fue realizada a principios de 1370 por Simon Autumanus, aunque el grueso del corpus plutarquiano fue traducido por Iacopo Angeli y Leonardo Bruni a principios del Quattrocento (Pade 2014: 538) No conocía tampoco la obra de Tácito, que sí era conocida por Boccaccio (Zaccaria 2001). Pero el rasgo medieval más destacado que caracteriza a su obra es su adscripción a un modelo historiográfico basado en los De viris illustribus, es decir, en la biografía de hombres ilustres. Los modelos biográficos medievales más importantes son el Liber de vita et moribus philosophorum del pseudo Walter Burley, el Speculum historiale, de Vincent de Beauvais, el Policraticus, de John de Salisbury, a quien Petrarca cita, el Chronicon de Benzo de Alejandría y los de De viris illustribus de Giovanni Colonna y Guglielmo da Pastrengo, ambos amigos personales de Petrarca (Sarnelli 2003)

4 Para Kempshall (2011: 489) hay una continuidad de ese modelo en Salutati y Bruni, ya que ambos autores, junto con Petrarca, comprenden la Historia bajo la Retórica epidíctica y deliberativa, que reciben de Cicerón, Quintiliano y la Rhetorica ad Herennium. Otra prueba que evidencia la continuidad de esta concepción es la falta de interés de Lapo da Castiglonchio y Guarino da Verona de traducir íntegramente el tratado historiográfico de Luciano de Samósata en el que cuestiona la relación entre la Historia y la literatura epidíctica (Kempshall 2011: 490-495) El autor ve una excepción en el prólogo a la Gesta Ferdinandi, que Lorenzo Valla escribe en 1445-1446 (Kempshall 2011: 497). Gary Ianziti (2012: 13) considera que la obra historiográfica de Bruni carece de un examen crítico de las fuentes. Para demostrar esta tesis, compara los textos de Bruni con sus fuentes principales (Plutarco, Villani, Polibio, Procopio, Jenofonte) y comprueba que los pasajes en los que difieren no están motivados por otra fuente que lo contradice sino por la orientación ideológica que se le quiere dar al texto. Guenée (1980) en cambio considera que la historia de los humanistas fue el comienzo de la autonomización con respecto a la Retórica y propuso su estudio más allá del modelo historiográfico medieval que la consideraba como una ciencia auxiliar al Derecho y a la Teología. En este sentido, comenta la carta de Lapo de Castiglonchio de 1437 y menciona a Bartolomeo della Fonte, profesor de la Universidad de Florencia, como el promotor de la primera Historia de la historiografía. Burke (2016) considera que con Petrarca se comienza a adquirir un sentido 
Encontramos una buena exposición de esa concepción en el prefacio largo al De viris illustribus ${ }^{5}$. Hay en ese prefacio algunas definiciones muy interesantes. En primer lugar, observamos un criterio para la selección de personajes. Petrarca aclara que quedan excluidos los seguidores de Minerva y solo se ocupará de los de Juno y Venus, es decir, que no vamos a encontrar ni filósofos ni poetas. En segundo lugar, tenemos un criterio de relevancia ¿Qué queremos saber de la vida de esos hombres ilustres? Solamente lo esencial: puesto que el objetivo principal es presentar esas vidas como ejemplos morales, se deben excluir todos los elementos que no conduzcan a ese objetivo. Aunque Petrarca hace una salvedad: es posible que se incluyan digresiones para deleitar al lector sobre las costumbres domésticas (virorum illustrium mores vitamque domesticam), sobre las conversaciones o las sentencias (et confabulationes ac voces sententiis plenas), sobre las frases graves y las ingeniosas (nunc peracuta, nunc gravia). En cuarto lugar, un criterio metodológico sobre el trabajo con las fuentes: Petrarca aclara que su objetivo no es investigar (quaero), sino coleccionar (colligo) el material, reunirlo de manera elocuente y con un estilo agradable para el lector. En quinto lugar, la postulación de un perfil del tipo de lector esperado. El autor habla allí de algunos nobles (militares viri) que, por falta de tiempo, leen un solo libro y cuestionan todo lo que lo contradiga. Se trata de una advertencia: el objetivo de esta colección de vidas es que los que se dedican a los asuntos públicos puedan acceder a un modelo de virtud tomado de la Antigüedad, pero eso no los convertirá en eruditos sobre la materia. Por último, un criterio moral: el lector no encontrará modelos perfectos, sino con algunas manchas. De hecho, si se buscaran ejemplos perfectos, el libro sería demasiado breve: «Si enim omnia prorsus illustria requirimus, exiguum teximus volumen, sed potius nullum» (Petrarca, 1955: $222-223)^{6}$.

Sin embargo, Petrarca no concibió la Historia solo bajo el modelo de los De viris illustribus. Para comprender qué pensaba el autor sobre la función de la Historia y su escritura será necesario el análisis de otro de sus proyectos: los Rerum memorandarum libri (de aquí en adelante Mem).

histórico del que carecía la Edad Media, no en cuanto a la narrativa y a los géneros historiográficos, sino con relación a tres elementos novedosos que serían el «sentido del anacronismo», la «conciencia de la necesidad de contrastación» y el «interés por las causas». Breisach (2008) considera que la desintegración de la historiografía medieval no fue obra de un autor particular, sino un largo proceso que va de 1350 a 1700 . Para un panorama general de la historiografía medieval y del Renacimiento v. Aurell, Balmaceda / Burke / Soza (2013) y Woolf (2012).

$5 \quad$ El De viris illustribus fue un proyecto de juventud que comenzó en 1338 y que escribió en paralelo al Africa. Interrumpe su escritura y los retoma entre los años 1341 y 1343 . Esa primera versión del texto contiene veintitrés biografías de hombres ilustres romanos (Dotti 2004: 66). Luego de abandonar el proyecto durante muchos años, lo retoma en 1353, pero esta vez con cambios radicales. Ya no se trata solamente de personajes históricos de la Antigua Roma, sino que se agregan diez personajes bíblicos, además de Jasón y Hércules. En esta versión, Petrarca incluye un largo Prefacio, que es el que analizamos aquí (Dotti 2004: 239) Ya en sus últimos años, alrededor de 1371, Francesco da Carrara le pide al poeta que retome la obra, con la intención de decorar la sala de su palacio con figuras históricas. Petrarca realiza una lista de treinta y seis personajes, esta vez solamente romanos, aunque los últimos doce son completados post mortem por Lombardo della Seta. Esta última versión incluye un Prefacio más breve, pero de contenido similar al anterior (Dotti 2004: 406).

6 'Si buscáramos que todos fueran absolutamente ilustres, tendríamos un exiguo, por no decir nulo, volumen'. 


\section{Valerio Máximo y los Rerum memorandarum libri}

Petrarca trabaja en la escritura de este texto entre los años 1343 y 1345, período que pasa en su mayoría en la ciudad de Parma, en el castillo de Guardasone gracias al ofrecimiento de su amigo Azzo da Correggio (Dotti 2004: 93). Petrarca afirma que la idea general de los $\mathrm{Mem}$ está basada en la clasificación de las virtudes que hace $\mathrm{Ci}$ cerón en el De inventione (II, 53, 156-60). Allí Cicerón explica cuáles son las partes de cada una de las virtudes cardinales. En el caso de la prudentia, sus tres partes son la memoria, la intelligentia y la providentia. La estructura de los Mem debía seguir ese esquema. Los libros II, III y IV están dedicados a esas tres partes de la prudencia, a los que Petrarca añade un primer libro sobre el ocio y la soledad. Es probable que el proyecto contemplara también las otras virtudes ${ }^{7}$. En ese caso, se trataría de un volumen muy importante.

Si bien el tema general está tomado de Cicerón, el modelo genérico y buena parte del contenido está inspirado en los Factorum et dictorum memorabilium libri, de Valerio Máximo. Recordemos que Petrarca ubicaba a este autor en primer lugar en la lista que mencionábamos supra, aunque eso no significa que lo estimara más que al resto. De hecho, en la Fam IV, 15 a Giovanni d'Andrea, el autor discute la presencia de Valerio Máximo entre los grandes filósofos morales de la Antigüedad, ya que según su criterio no está a la altura de Platón, Aristóteles, Cicerón o Séneca. En un pasaje del cuarto libro (IV, 97) lo acusa de oscuro (obscurus) e incluso mentiroso (mendax), porque omite alguna información que Petrarca pudo encontrar fácilmente en Cicerón. Hay que agregar que no solamente Petrarca estaba interesado en Valerio Máximo. Dos conocidos de Petrarca, Dionigi da Borgo San Sepolcro y Benvenuto da Imola, escriben comentarios a su obra (Nolhac 1907: 46). Es también curioso el juicio de los humanistas sobre Valerio Máximo. Para Salutati, por ejemplo, era un autor más cercano a la moral que a la historia: «non tam excerptorem historiae, quam moralium praeceptorem uberem» (Salutati 1891: 10) ${ }^{8}$. El juicio de Erasmo no era tan benevolente: «Valerius Maximus non magis Ciceronis similis quam homini mulus» (Erasmo 1703: 1006) .

¿A qué se debe esa ambivalencia? ¿Por qué si Petrarca no lo consideraba un gran autor utilizó su libro como modelo? Las respuestas a estas preguntas deben buscarse en las características de la obra de Valerio Máximo. Se trata fundamentalmente de un libro de exempla que reúne dichos o hechos curiosos sobre personajes históricos y otros sobre personajes ignotos, que utilizaban los oradores para tener un ejemplo a mano a la hora de elaborar sus discursos ${ }^{10}$. El problema para clasificar este texto estriba en su estrecha relación con la fábula (de animales). Algunas investigaciones han demostrado que ambos géneros están emparentados no solamente por su función

\footnotetext{
Algunos manuscritos conservados presentan tres capítulos de un libro inconcluso sobre la modestia, que según la lista ya mencionada de Cicerón pertenece a la templanza. En otros se ha descartado ese libro inconcluso. Ello se debe a que Petrarca nunca dio a conocer los Mem en vida. Tras su muerte en 1374, Lombardo della Seta copia el texto con esos capítulos, mientras que la copia realizada por Tedaldo della Casa no los incluye (Petoletti 2014: 13).

'no tan experto en historia, como rico en preceptos morales'.

'Valerio Máximo no es más parecido a Cicerón que un hombre a una mula'.

10 En este caso, exemplum hace menos referencia a la ejemplaridad moral que al sentido de ejemplo como un caso o una muestra dentro de un conjunto. Para los diferentes sentidos del término exemplum y sus usos tanto en la Antigüedad como en la Edad Media y el Renacimiento, v. Lyons (1989: 6-20)
} 
retórica, sino también por su filiación helenística y su transmisión siempre sujeta a las variaciones e inversiones ${ }^{11}$.

Otra línea de investigación incluye el modelo de Valerio Máximo bajo el concepto de "concordancias de la Historia". Dentro de este género se encontrarían todos aquellos textos que no presentan una Historia siguiendo un esquema cronológico lineal y tampoco el desarrollo de una vida completa, sino un conjunto de personajes presentados bajo el amparo de una característica común ${ }^{12}$. Tanto si lo consideramos libro de exempla o vinculado al modelo de las «concordancias de la Historia» queda claro que el juicio negativo está relacionado con su adscripción a los «géneros de escuela». Si bien el De viris estaba pensado para un público no especializado y no carecía de una función pedagógica, gozaba de un prestigio mayor por una larga tradición que se remonta a san Jerónimo. En este caso, Petrarca se embarca en un monumental proyecto que parece desproporcionado si uno considera que sus otros dos grandes proyectos en lengua latina todavía sin concluir, el De viris y el Africa, pertenecen a la alta literatura. Intentaremos responder a la pregunta de por qué Petrarca escribe los Mem siguiendo a Valerio Máximo y qué uso le da a ese modelo, pero antes será necesario analizar otro texto biográfico-histórico que el autor comienza unos años más tarde ${ }^{13}$, el libro II del De vita solitaria.

\section{El De vita solitaria}

En el libro II del De vita solitaria el elenco de vidas comienza con los eremitas y anacoretas, continúa con los profetas hebreos, sigue con los Padres latinos, pasando por los santos fundadores de las órdenes monásticas y mártires. Todos ellos son claros ejemplos de amor por la soledad y desprecio por los bienes mundanos. Pero en el parágrafo IX, Petrarca introduce ejemplos de la vida activa a través de un recurso interesante: una digresión sobre la guerra de los cien años que se supone un agregado posterior a la primera redacción del texto ${ }^{14}$. Estas noticias sobre la guerra son utiliza-

11 Cascón Dorado (1987) señala cinco características comunes: 1. Intención moralizadora, 2. Difusión simultánea en época helenística por influjo de la Retórica, 3. Origen ligado a formas literarias mayores (teatro, historia, etc.) y dependiente de otras menores (sentencias, máximas, etc.), 4. Estructura de tres partes: promitio, narratio, epimitio, 5. Enorme difusión durante la Edad Media. El autor encuentra fenómenos similares en su transmisión: cambio en los personajes, cambio en las situaciones argumentales, ampliaciones, abreviaciones, duplicaciones, contaminaciones, cambio en la intencionalidad. De hecho, encontramos un fenómeno de este tipo en uno de los exempla de Mem, el II, 60, que cuenta la historia de Dino, muy semejante a Decamerón VI, 9, que narra un acontecimiento similar pero protagonizado por Guido Cavalcanti. Petrarca y Boccaccio no se conocían cuando escribieron estas obras y ninguno de los dos pudo haberla tomado del otro, sino que la recogen de una fuente desconocida (v. Olson 1983). De todos modos, los exempla de los Mem no siguen este formato en todos los casos.

12 Para Cherchi (2002) los Mem pueden agruparse con la Commedia de Dante, el De casibus virorum illustrium de Boccaccio y los Trionfi del mismo Petrarca como antecedentes de las llamadas "Concordancias de la Historia", muy populares en los siglos XV y XVI. Textos como los Comentarii urbanii de Raffaele Maffei (1506) o la Officina partim historiis partim poeticis referta disciplinis de Ravisius Textor (1520) y muchos otros seguirían el modelo de Valerio Máximo

13 Según Martellotti (1955), Petrarca comienza este texto en 1346 en Vaucluse y agrega modificaciones hasta 1366, cuando lo da a conocer. Para un estudio pormenorizado de las adiciones que hace Petrarca durante esos años v. Ullman (1973).

14 Como Petrarca afirma que los ingleses y los franceses pelean hace veinticinco años, Martellotti supone que el pasaje en cuestión es un agregado de 1362. Aunque es probable que sea anterior, ya que también se afirma que 
das como preludio para la crítica a los gobernantes modernos y esa misma crítica es el motivo para introducir el elogio a los gobernantes del pasado.

De esta manera Petrarca incorpora personajes asociados a la vida activa en un texto que en principio es sobre la soledad y el retiro. Así aparecen los Escipiones, César Augusto y otros héroes romanos ya presentes en el De viris illustribus. Sin embargo, una vez finalizado el elogio, Petrarca aclara que estos héroes dieron su vida por Roma porque Roma era justa, pero a pesar de eso fueron injustos con Dios («iniustos tamen in Deum fuisse»). A partir de esta aclaración el texto vuelve a su cauce original.

En el parágrafo XI, anuncia que hablará de ejemplos extranjeros («ex alio genere»). Recoge para ello un texto atribuido a Ambrosio sobre los brahmanes de la India y el Adversus Iovinianum de san Jerónimo ${ }^{15}$. Luego de mencionar su continencia, pureza del alma, meditación silenciosa y frugalidad de las costumbres, surge el ejemplo de Calanus, aquel que se inmoló ante Alejandro y profetizó su muerte, según las leyendas. A partir de la mención de este personaje, Petrarca toma distancia no solamente del mismo Calanus, sino de su pueblo. Rechaza la desnudez, el descuido animal por el sueño y la comida («incuriositas belluina somni cibique») para luego proponer, citando a Cicerón, un tipo de vida mesurado, en el que no se siga la perversa costumbre de anticiparse a la muerte («perversus mos mortis anticipande»), ya que es contraria tanto al cristianismo como a los filósofos paganos, un desprecio del mundo («contemptus mundi») no mayor que el justo.

La lista continúa con algunos filósofos y poetas: Platón, Plotino, Pitágoras, Parménides y Demócrito entre los filósofos de la Antigüedad, a los que se añade Pedro Abelardo; Entre los poetas, se encuentran Homero, Orfeo, Lino, Museo, Virgilio, Horacio y Ovidio. Un espacio aparte les reserva a los oradores, Séneca, Cicerón y Demóstenes, y luego un segundo grupo de filósofos: Anaxágoras, Jenócrates, Zenón, Carnéades, Crisipo y Diógenes, y Solón. Y la lista continúa con Julio César, César Augusto, Diocleciano, Numa Pompilio, Rómulo, Aquiles y Hércules y los dos africanos. La conclusión del texto es una defensa del otium negotioso que da sentido a la variedad de la lista: «Hec igitur summa est: admitto ad otium non hec vento mobiliora, sed mansura negotia, quorum finis est non labor et questus et dedecus, sed delectatio et virtus et gloria» (Petrarca, 1955b: 556) ${ }^{16}$.

El objetivo de las vidas que se reúnen en este libro es justamente proponer esta unión de delectatio, virtus y gloria, o dicho de una manera más simple, un modelo de hombre que, apartándose de los extremos del otium y el negotium, pueda combinar ambas tendencias. Ese mismo objetivo se presenta en los Mem, pero será preciso analizar cómo su adscripción al género de "conjunto de exempla" está vinculada con esa intención y de qué manera se incorpora un elemento que no encontramos en los otros textos: un fragmento encomiástico sobre un personaje contemporáneo de Petrarca y que tiene un lugar central en el texto: Roberto de Anjou.

el hijo del rey de Francia está prisionero, cuando se sabe que obtuvo la libertad en mayo de 1360, a partir del tratado de Brétigny. Petrarca también comenta estos hechos en la Fam, XV, 7 (Baldassari 2006: 181).

15 Se trata de una traducción de un texto griego escrito por Palladius en el siglo V d.C. Las dos versiones latinas que se conservan, Vat. Lat 281 (1374) y Vat. Lat. 282 (Siglo XI), se adjudicaron a san Ambrosio. Petrarca aclara en el pasaje que algunos afirman esa autoría (a nonnullis ostenditur) y luego aclara que es de Paladio (non Ambrosii sed Palladii liber est) V. Pritchard (1993).

16 'Entonces la conclusión es: admito la ocupación en el ocio, no aquella que mueve el viento, sino una más estable, cuyo fin no es la fatiga, ni el lamento, ni la vergüenza, sino el deleite, la virtud y la gloria’. 


\section{El equilibrio entre otium y negotium}

En cada uno de los libros, Petrarca organiza el material en ejemplos romanos y extranjeros, como lo hace Valerio Máximo, pero añade además algunos ejemplos modernos. De las tres secciones la moderna es siempre la más breve y, en el caso del primer libro, solo incluye como ejemplos de ocio y soledad al rey Roberto de Anjou. Pero antes de entrar en la descripción del angevino, será necesario profundizar en la descripción del texto como unidad y su relación con el modelo de hombre que combina el otium y el negotium.

En cada una de las secciones Petrarca incluye una serie de personajes. En la siguiente sección, alguno de esos personajes puede reaparecer al hilo de otro tema. Es decir, que así como el rey Roberto tiene tres entradas, otros personajes también aparecen en varias oportunidades. Por ejemplo, César Augusto aparece once veces, sin contar cuatro respuestas ingeniosas que le dieron a él personajes ignotos; Cicerón, seis veces; Julio César, cinco; Sócrates, cuatro; Platón, tres; por mencionar solo algunos. En todos ellos, Petrarca busca abordar al personaje desde un punto de vista diferente en cada sección. Tomemos el caso de Augusto. En la sección «De otio et solitudine», comenta a través de Séneca (De brev. Vitae, IV) una carta en la que el Emperador menciona sus ansias de retiro. En «De studio et doctrina», alaba su interés por las letras y la filosofía, además de enumerar una serie de obras que escribió, el poema Ergone supremis, una tragedia inconclusa y un libro en hexámetros titulado Sicilia. En «De ingenio et elocuentia», elogia su estilo claro y directo. En «De facetiis ac salibus illustrium» refiere las respuestas rápidas y graciosas, que incluyen burlas a personas con defectos físicos. En «De solertia et calliditate» comenta que Augusto cometía adulterio, y que de esa manera podía combatir las conjuras, ya que conocía por las mujeres las actividades de los maridos. De esta manera se va construyendo un retrato dinámico a partir de diferentes puntos de vista.

Por otro lado, otras dos características colaboran en el mismo sentido: las anécdotas sobre personajes ignotos y las historias cotidianas sobre personajes ilustres. En las palabras preliminares de la sección sobre chistes y dichos mordaces de hombres ilustres ( «De facetiis ac salibus illustrium») el autor aclara que no hablará de la elocuencia que Cicerón contempla en el De oratore, sino de conversaciones cotidianas («quotidianis sermunculis»). La mayoría de las anécdotas de esta sección están extraídas del libro II de las Saturnales de Macrobio y pertenecen a personajes ilustres, pero también hay algunas anónimas en donde lo importante no es ya el protagonista como la narración misma. Tanto unas como otras consiguen el mismo efecto: acercar lo bajo y lo alto y comprender la acción humana en un mismo plano, donde un rey puede hacer una broma y un personaje ignoto es capaz de un ingenio pocas veces visto.

En su libro sobre el exemplum, John Lyons (1989: 26-34) enumera siete características sobre el género ${ }^{17}$. Dos de ellas resultan relevantes para el análisis de los Mem. La primera, llamada «multiplicidad e iteratividad», está relacionada con la repetición: la multiplicidad refiere a la diversidad de ejemplos que pueden darse para demostrar un punto y la iteratividad enfatiza la forma en que un ejemplo representa muchos eventos similares. En cualquier caso, cuando se usa como ejemplo, una entidad pierde su

Las siete características son: 1) Iteratividad y multiplicidad, 2) Exterioridad, 3) Discontinuidad, 4) Rareza, 5) Artificialidad, 6) Indecidibilidad, 7) Exceso 
autonomía y singularidad. La segunda característica que consideramos es aquella que Lyons llama «rarity» y que refiere a un hecho extraordinario, fuera de lo común. Es decir, que por más extraño que sea un hecho siempre habrá otro con el que compararlo, o que puede ocupar su lugar. Esa tensión entre lo singular y lo múltiple aparece en los Mem de una manera particular, ya que en el caso de personajes que el autor considera importantes se extiende mucho más y excede el uso del exemplum para ingresar en algo más similar a la biografía. Por ejemplo, en el caso de Platón se detiene en su viaje a Egipto, evalúa la posibilidad de que haya conocido a Jeremías y cita a san Agustín para refutarlo. Allí se observa la necesidad de construir una narración biográfica que aspire a cierta totalidad, o en todo caso, es claro que no se trata de una simple anécdota. Es decir, que las múltiples anécdotas breves sobre un personaje contribuyen a realizar un retrato dinámico, que a su vez tienden a mostrar el equilibrio entre otium y negotium que observamos supra, pero a su vez resulta necesario destacar a algunos personajes sobre el telón de fondo de lo que tomado por separado puede resultar extraordinario pero que ubicado en una secuencia pierde singularidad.

Veremos que los tres pasajes sobre Roberto de Anjou deben comprenderse en relación con estas características de la obra.

\section{El elogio a Roberto de Anjou}

El 16 de enero de 1343 muere en Nápoles el rey Roberto de Anjou. Su muerte fue para Francesco Petrarca motivo de un gran pesar. Recordemos que el rey patrocinó la coronación capitolina del poeta en 1341 y que jugó un papel importante en lo que en teoría debía ser el resurgimiento de un modelo literario en el que la poesía emerge como vehículo de elogio hacia los poderosos y el poder patrocina las letras para obtener fama y gloria ${ }^{18}$. Esta mutua dependencia entre poetas y reyes es uno de los núcleos temáticos de la Collatio Laureationis, la exposición que Petrarca hace en ocasión de su coronación, y es un tema recurrente en toda su obra. En la Fam IV, 7, al rey Roberto lo felicita por haber renovado una costumbre perdida y lo compara con César Augusto y a sí mismo con Horacio y Virgilio ${ }^{19}$. Por eso, la muerte del monarca significa más que la muerte de un amigo para Petrarca, que tenía la intención de escribir un libro completo sobre su vida (Mem III, 96).

Pero Petrarca no fue el primero en elogiar al rey Roberto, sino que constituye un eslabón de una larga cadena de autores, parte de un sistema de mecenazgo y de propaganda política que el propio rey incentivaba ${ }^{20}$. En muchos de esos casos, el foco

18 Petrarca hereda de la Retórica clásica la idea de que la poesía épica pertenece a la Retórica epidíctica. En la Collatio Laureationis cita a Ovidio, Estacio, Virgilio, Lucano, Cicerón, Claudiano y Horacio para argumentar a favor de la idea de que el elogio de los poetas a los Césares redunda en la obtención de la gloria de ambos. Sobre las diferencias entre la poesía y la Historia, en el mismo texto afirma que la divergencia entre historiadores, poetas y filósofos es similar a la que existe entre el cielo nublado y el cielo soleado, es decir que la poesía mostraría el mismo objeto solo que bajo un velo alegórico. Sobre la relación entre épica y encomio en el Renacimiento, v. Vickers (1983).

19 Otros textos en los que se elogia a Roberto son: Met, 1, 4 de 1339, donde Petrarca comenta el viaje que hizo el rey a Vaucluse en 1320, Buc. Carm. II (Argus), Africa I, 79, IX, 421, Epyst. II, 8, Tr. Fam. II, 160-61, Post. 29-32, Fam. I, 2. 9-11, IV, 2, IV, 3, IV, 7, VI, 5, XII, 2.

20 Kelly (2003) demuestra que el mecenazgo funcionaba sobre todo con teólogos y clérigos. Menciona a François de Meyronnes, Giovanni Regina, Federico Franconi, Guglielmo da Sarzano, Andrea da Perugia, Agostino d'An- 
de la laudatio está puesto en la figura del rey filósofo. Esa imagen no era de ningún modo arbitraria, sino que formaba parte de lo que el mismo rey quería que se supiera de sí. Se sabe que daba a conocer sermones y tratados teológicos de su supuesta autoría (Kelly 2003: 8). De todos modos, veremos que el elogio que realiza Petrarca tiene algunas características especiales en línea con lo que ya hemos observado supra. Por otro lado, la inclusión de fragmentos encomiásticos está relacionada directamente con el modelo de Valerio Máximo, que combina una modalidad didáctica con una modalidad epidíctica (Nenadic / Pozzi 2014).

Los fragmentos dedicados al rey Roberto son tres (I, 10 y 37; III, 96). El primero de ellos se encuentra en una de las dos secciones introductorias del libro dedicada al ocio y la soledad («De otio et solitudine»). Es el único ejemplo moderno que da Petrarca en esta sección. Allí se describen las costumbres del rey y su afición a la ballesta:

Fuit illi in urbe neapolitana palatio confine pomerium, prealtis circumseptum menibus et pelago non modica ex parte circumfluum. Huc modo cum paucis, modo cum ingenti procerum catherva quotidie veniens balista lusitabat; idque tam sedulo, ut confestim tantum erat et tam ad omnia versatile celestis acumen ingenii eius artificii magistros post tergum linqueret. (Petrarca 2014: 36) ${ }^{21}$

Puede observarse que el concepto de otium no representa, como en otros textos de Petrarca, la dedicación a las letras o la devoción religiosa, sino algo más cercano a la diversión y el esparcimiento. Esto es notorio en los fragmentos que acompañan a Roberto en la misma sección, por ejemplo en la anécdota que el autor extrae de Valerio Máximo sobre Sócrates tocando la lira y jugando con sus hijos: «Quod parcius miror, dum eundem arundine cruribus inserta colludentem infantulis suis intueor. Quod cernens familiarissimus sibi risisse fertur Alcibiades» (Petrarca 2014: 36) ${ }^{22}$. El énfasis puesto en el juego y la infancia caracteriza el comienzo de un recorrido que terminará en la muerte. Lejos de elogiar los orígenes nobles de Roberto, Petrarca elige una escena inicial que lo ubica a la par de todos los hombres, destacándose en el juego por empeño y habilidad, y no por la obsecuencia de sus súbditos.

El segundo fragmento sobre el rey $(\mathrm{Mem}, \mathrm{I}, 37)$ se encuentra en la segunda sección introductoria dedicada al estudio y la doctrina ( $\langle$ De studio et doctrina»). Al igual que en la sección anterior, es el único ejemplo moderno. El autor comienza aclarando que el rey no se dedicaba al estudio como los otros personajes de la sec-

cona, Dionigi da Borgo San Sepolcro, Remigio de Girolami, Ptolomeo de Lucca y Bertrand de Turre. Todos ellos, con distinto grado de cercanía y compromiso con Roberto, recibieron su apoyo y escribieron elogios. La autora también demuestra que el contenido de la biblioteca de Roberto respondía al gusto medieval: sus títulos versaban sobre Teología, Derecho, Medicina y Astronomía. En la misma línea rechaza la idea de que la corte angevina estuviera formada por un círculo de humanistas. Niccolò d'Alife, Barbato da Sulmona y Giovanni Barrile, los supuestos promotores del humanismo napolitano, tenían escasa influencia en Roberto y eran más bien personajes marginales en la corte.

21 'Tenía en la ciudad de Nápoles un jardín junto a su palacio, delimitado de un lado por altos muros, y rodeado en gran parte por el mar. Iba cotidianamente a ese lugar, a veces con pocos compañeros, otras con una gran cantidad de nobles, y se entretenía con la ballesta, y con tal empeño que pronto dejó atrás a los maestros de este arte: tan grande y tan versátil fue la agudeza de su genio divino'.

22 'Me sorprendo poco cuando lo veo jugar con sus hijos a caballo de una caña. Se dice que Alcibíades, su íntimo amigo, reía cuando veía la escena’. 
ción («Is enim non post labores studiorum, quod de multis vidimus»), pero que siempre quería tener libros cerca («libros prope se voluit»). Luego, como en la epístola mencionada arriba, lo compara con César Augusto:

Et quod de Cesare Augusto diximus, hic multo minore et quasi nulla prorsus subsistente materia diligentissime semper custodivit, ut ingenia seculi sui complecteretur benignitate regia et inventiones novas recitantibus, non tantum parientissimus auditor, sed plausor etiam et humanissimus fautor assisteret. (Petrarca 2014: 88) ${ }^{23}$

A continuación, Petrarca menciona que en una conversación con el rey surgió el tema de las costumbres del rey de Francia que no se ocupaba de la educación de sus hijos, de manera que se construye como contrafigura. Por un lado el rey filósofo («senem philosophum et rege»), que a pesar de no dedicarse por entero al estudio, lo fomenta, y por el otro, un rey que no valora las letras. Tomando como punto de partida esta comparación, el rey le confiesa al autor que, si tuviera que elegir entre las letras y el poder, elegiría las letras: «Iuro dulciores et multo cariores michi literas esse quam regnum; et si alterutro carendum sit, equanimius me dyademate quam literis cariturum» (Petrarca 2014: 90) ${ }^{24}$.

Sin embargo, Petrarca se encarga de aclarar que en el terreno de la poesía Roberto desconoce completamente lo que el autor le comenta durante el examen previo a la coronación $y$, asombrado, le reconoce que hubiera dedicado más tiempo a la poesía si hubiera sabido de ella antes. Esa tensión entre el conocimiento del rey y el conocimiento del poeta se observa más claramente en Itinerarium ad sepulcrum Domini $^{25}$. Allí el autor trata el mismo episodio del examen napolitano. Durante esos días, ambos salían a cabalgar y conversaban sobre distintos temas. En una de esas ocasiones el rey formula una pregunta sobre la presunta dedicación de Virgilio a la magia. Petrarca niega este hecho y lo adjudica a la leyenda:

Inter Falernum et mare mons est saxeus, hominum manibus perfossus, quod vulgus insulsum a Virgilio magicis cantaminibus factum putat. Ita clarorum fama hominum, non veris contenta laudibus, sepe etiam fabulis viam facit! De quo cum me olim Robertus regno clarus, sed preclarus ingenio ac literis, quid sentirem multis astantibus percuntatus esset, humanitate fretus regia, qua non reges modo sed homines vicit, iocans nusquam me legisse marmorarium fuisse Virgilium respondi, quod ille serenissime nutu frontis approbans, non illic magie sed ferri vestigia esse confessus est. (Petrarca 1997: 36) 26

23. 'Es lo mismo que dijimos de César Augusto, que siempre buscó, a pesar de que a veces la materia fuese menor o casi nula, abrazar los ingenios de su propia época con real benevolencia, escuchar con infinita paciencia y no solo elogiar, sino también promover con la máxima cordialidad a quienes recitaban nuevas invenciones'.

24 'Juro que las letras me son más dulces y más queridas que el reino. Y si fuese privado de ambas cosas, echaría de menos las letras, más que la corona’.

25 Se trata de una guía que Petrarca le dedica en 1358 a Giovanni Mandelli, quien lo había invitado a peregrinar a Jerusalén. Petrarca se excusa por su mala salud, pero a cambio le ofrece este texto (Gazzola 2005).

26 'Entre Falerno y el mar hay una montaña rocosa, perforada por las manos del hombre, que el vulgo ignorante cree que fue realizado por las artes mágicas de Virgilio. Así es la fama de los hombres ilustres, cuando no están satisfechos con elogiarlos con verdades, a menudo inventan ficciones. Cuando en una oportunidad el rey Roberto, conocido por su buen gobierno, pero más aún por su ingenio y talento para las letras, me preguntó en 
De esta manera, se logra una inversión en los códigos de la laudatio o, en todo caso, un particular modo de utilizar el elogio de otro para en realidad ubicarse a sí mismo como objeto. No es el poeta el que elogia al soberano por su conocimiento, sino por su sabiduría demostrada en el acto mismo de escuchar al poeta.

El tercer fragmento dedicado al rey $(\mathrm{Mem}$, III, 96) se encuentra en la sección sobre la habilidad y el ingenio ( De solertia et calliditate»). Aquí Petrarca describe la muerte del monarca. En su lecho de muerte, no se lamentó ni lloró, sino que aguardó lo inevitable con la fortaleza propia de un rey filósofo y pronunció las siguientes palabras: «Hoc istud consilio, hod illum periculum declinate. Sic sum subiectis, sic cum amicis, sic cum hstibus vivite. Hec atque hec inter vos precept servate. Et valete nostri memores» (Petrarca, 2014:352) ${ }^{27}$.

Esta escena es complementaria con la caracterización hecha en los otros fragmentos. Si en el pasaje visto anteriormente se mostraba al rey en su relación con las Letras, aquí asistimos al producto de ese aprendizaje. La calma en el momento de la muerte evidencia que la sabiduría tiene una aplicación práctica, necesaria para enfrentar los embates de la fortuna, que el rey pudo extraer no solo de los libros, sino también de su relación con el propio Petrarca. El tipo de sabiduría que Petrarca elogia en Roberto está lejos de aquella que practicaba el rey y más cerca de la que promocionaba Petrarca: la filosofía moral, que ayuda a enfrentar la muerte con actitud estoica. La discontinuidad entre los tres pasajes no impide una lectura secuencial según la cual el interés del rey por los juegos y el ocio es condición de su apoyo a las Letras y su descubrimiento de la poesía concluye en uno de los bienes más preciados: la calma ante la muerte.

\section{Los Rerum memorandarum libri en la producción del autor}

La incorporación del angevino en el conjunto de exempla que forman los Mem debe ser comprendida en relación con las características particulares del texto. Por un lado, al tratarse de un modelo historiográfico menor, es posible la aparición de un personaje contemporáneo junto con los clásicos. Esa yuxtaposición se produce de manera diferente en los otros textos sobre materia histórica ${ }^{28}$. Por otro lado, las numerosas entradas sobre el mismo personaje brindan la posibilidad de realizar un retrato dinámico y de esta manera el elogio se construye no sobre la base del ejemplo de virtud intachable, sino sobre el correcto equilibrio entre el otium y el negotium. Roberto, como muchos otros personajes mencionados en el texto, ha sabido combinar las letras, el ocio y los placeres mundanos. Los términos en los que Petrarca

presencia de muchos qué pensaba yo de ese asunto, confiando en la humanidad del rey, que superaba no solo la de otros reyes, sino la de todos los hombres, le contesté bromeando que no había leído que Virgilio fuese un escultor, a lo que él, serenamente y con gesto de aprobación, confesó que no había allí restos de magia, sino del uso de hierro'.

27 'Eludan los peligros con este consejo. Vivan de la misma manera con los súbditos, con los amigos y los enemigos. Observen entre ustedes estos preceptos. Recuérdenme'.

28 Hay una sola mención de Roberto en el final del libro IX del Africa: «magnanimum Mors importuna Robertum/ Intempestive mundo subtraxit egenti» 'La muerte inoportuna sustrajo intempestivamente al magnánimo Roberto de este pobre mundo'. En ese último libro también aparece el propio Petrarca y el título del poema Africa como continuadores de la costumbre de la coronación poética que inauguran Escipión y Ennio. En los De viris no hay ninguna mención de Roberto. 
construye la laudatio responden también a esa lógica. La gloria de Roberto no está construida sobre éxitos militares, ni grandes gestas heroicas, sino a partir del uso provechoso del ocio, el interés y apoyo a las letras, y la calma ante la muerte, que no es otra cosa que la consecuencia de esos pasos previos.

Esa descripción es la expresión de una concepción de la Historia y del texto histórico muy diferente a la de la épica del Africa y la biografía del De viris. Los Mem están construidos a partir de la materia que en aquellos se considera digresión. Hay entonces una diferencia clara en el criterio de selección. Es una Historia de temas menores, en la que, como dice el autor, tratará más del ingenio que del estudio («non tam studium quam ingenium», Mem, II, 15) y también una forma de acercar el pasado al presente. $\mathrm{Si}$, como afirma en el prólogo al De viris, los príncipes de su tiempo ofrecen materia para la sátira y no para la Historia, su inclusión en una obra dependerá de qué tipo de Historia trate. En una Historia sobre las hazañas es posible que Roberto no esté a la altura de César Augusto, pero en un libro como los Mem es posible.

Por otro lado, la comprensión de este texto contribuye a la larga discusión acerca del modo en que Petrarca concibe la relación entre el pasado clásico y su propio presente. Leemos a menudo que sentía un gran rechazo por su tiempo (Mommsen 1942) y, de hecho, el pasaje más citado de los Mem es aquel en el que afirma que se encuentra en el confín de dos pueblos (I, 19). La idealización de los clásicos lo conduce a la construcción de arquetipos que hay que seguir. Pero también es posible observar otro tipo de relación con los clásicos vinculada a su lectura de las Confesiones de san Agustín y las Cartas a Ático de Cicerón, textos en los que descubre no ya ejemplos intachables de virtud, sino más bien hombres en conflicto con los cuales es posible identificarse. Thomas Greene (1982) plantea que durante el Renacimiento se utilizaron cuatro formas de imitatio: una primera que llama reproductiva, en la que el subtexto clásico es un modelo inmóvil y que ejemplifica con el Africa; una segunda que llama ecléctica y que está más vinculada a las alusiones poéticas; una tercera que denomina heurística y que ya implica una toma de distancia con el modelo, ejemplificada a través de las cartas de Petrarca del último libro de sus Familiares a Tito Livio, Homero, Cicerón, etc.; y una cuarta, la dialéctica, que produce una fuerte tensión entre el modelo y su imitación. Ejemplos de este último procedimiento son el Secretum de Petrarca y el Elogio de la locura de Erasmo. Los Mem y el elogio del rey Roberto de Anjou se sitúan en esa línea de lectura en la que la biografía se hace un género efectivo cuando se aparta del ejemplo virtuoso y, por lo tanto, se aleja de la imitatio reproductiva. En el Secretum ese modo de leer es muy claro:

inter procellas meas fluctuationis tue vestigium recognosco. Ex quo fit ut, quotiens Confessionum tuarum libros lego inter duos contrarios affectus, spem videlicet et metum, letis non sine lacrimis interdum legere me arbitrer non alienam sed propriam mee peregrinationis historiam. (Petrarca 2011: 130) ${ }^{29}$

Petrarca encuentra en Valerio Máximo un modelo historiográfico acorde con este tipo de lectura, que busca los puntos de comparación e identificación con los antiguos no en su perfil heroico, sino en un aspecto que, simplificando mucho, podríamos lla-

29 'Entre mis turbulencias y tus fluctuaciones reconozco una semejanza. Por ello, cada vez que leo los libros de tus Confesiones, me encuentro entre dos sentimientos contrarios, la esperanza y el miedo, y a veces, no sin lágrimas en los ojos, me parece estar leyendo no una historia ajena sino la de mi propia peregrinación'. 
mar humano ${ }^{30}$. Por eso el proyecto historiográfico de Petrarca fracasa. En la medida que para él la Historia no es más que otra forma del discurso pedagógico laudatorio, dirigido en gran parte a la formación de las clases dirigentes, deja de ser efectivo cuando los modelos humanos no son perfectos. Algunos estudios plantean que Leonardo Bruni, ya en el siglo XV, separó la Historia del encomio (Hankins 2000). Bruni escribe la Historia de Florencia en doce libros (Historiarum Florentini populi libri XII). Flavio Biondo, contemporáneo de Bruni, escribe una Historia de la Edad Media en treinta y un libros (Historiae ab inclinatione Romanorum imperii, cf. Delle Donne 2016). Evidentemente, el recelo que manifiesta Petrarca contra la minuciosidad y el detallismo de los historiadores perdería sentido para algunos humanistas del siglo XV. Por otro lado, se separan la Historia y la biografía. Bruni escribe biografías de Cicerón y Aristóteles y unas vidas paralelas de Dante y Petrarca. Queda claro que el interés por la biografía permanece, pero al mismo tiempo surgen nuevos modelos historiográficos que responden a la necesidad de comprender largos procesos históricos. Para Petrarca en cambio, la Historia está conformada por una sucesión de retratos.

Sin embargo, los Mem son la prueba de que esa concepción ya está en crisis. Sabemos que abandona este proyecto en 1345. El 23 de febrero de ese año huye de una Parma asediada por los Gonzaga y los Visconti. Luego de un ajetreado viaje, llega a Verona, donde realiza el famoso descubrimiento de las Cartas a Ático ${ }^{31}$. Para Petoletti (2014: 11), el proyecto de reunir sus propias epístolas Familiares, inspirado por la lectura de las cartas de Cicerón, reemplaza de alguna manera a un texto de carácter fuertemente tradicional y de sabor enciclopédico. Ugo Dotti (2004: 128) también considera que hay una diferencia muy marcada entre este texto, que describe como trabajo artificial, zibaldone de anécdotas y colección de noticias de estilo medieval, y otras obras de Petrarca. Para Paolo Cherchi, que considera el texto en relación a las "Concordancias de la Historia", el creciente interés de Petrarca por construir una autobiografía lo lleva a elaborar en los Trionfi una síntesis entre el modelo de Valerio Máximo y la Commedia de Dante.

Se sabe que, aunque el autor haya abandonado el texto, utilizó muchos de sus pasajes en la composición de los Remediis utriusque fortune (Boni 1949). Por otro lado, hemos visto que en el De vita solitaria, texto al que el autor dedica muchos años, se pueden encontrar afinidades con los Mem en cuanto a la utilización de la biografía con la intención de proponer un equilibrio entre otium y negotium. En todo caso, esa búsqueda a través de diferentes géneros y propuestas estéticas tan diferentes es la demostración de que una de las mayores preocupaciones de Petrarca era encontrar un tipo de texto diferente a los modelos que sigue tanto en el De viris como en el Africa, capaz de vincular el pasado con el presente de una manera más eficaz. El problema es que esa búsqueda implicaba la utilización de géneros menores. Es

Esto ubicaría a los Mem en línea con lo que algunos investigadores (Kelley 1970, Lyons 1989) llaman la «crisis de la ejemplaridad en el Renacimiento». Rigolot (1998) plantea que los términos de las lenguas vernáculas derivados del latín exemplum, son más cercanos al sentido de 'muestra', que de 'modelo'. La pregunta que guía su artículo es si esta crisis de la ejemplaridad se traduce en una nueva concepción de la Historia que se aparta de las explicaciones mágicas. Tras un completo estado de la cuestión que considera las tesis de Foucault en Las palabras y las cosas y al Nuevo historicismo, concluye que el uso del exemplum como guía moral comienza a perder fuerza como modelo literario e interpreta esto como un elemento digno de consideración en el debate por el libre albedrío y la representación de la contingencia y la singularidad. Para Anthony Grafton (2011) en cambio, estos "géneros escolares" como los Mem tenían el propósito de domesticar la lectura con la intención de comprender a los antiguos en términos cristianos e imponer modelos de conducta.

31 Petrarca relata este viaje en la Fam, V, 10. 
interesante que los juicios sobre el texto que acabamos de considerar apunten a ciertos rasgos enciclopédicos como tradicionales o incluso medievales. Ello nos habla no solamente de una falta de originalidad del autor, sino también de una concepción histórica que vincula esa repetición acrítica de ideas con lo medieval.

Sin embargo, la figura de Roberto de Anjou en el texto se impone como una señal de un intento de hacer confluir el elogio de un personaje moderno con anécdotas sobre grandes personajes de la Historia, pero vistos desde una perspectiva que los humaniza. Esa confluencia se da también en el plano de la forma en la medida en que este encomio vendría a explicar el equilibrio entre biografía y exemplum: la laudatio precisa de la singularidad propia de la biografía, pero los términos en los que Petrarca decide presentarla, es decir, los de un rey filósofo que supo llevar a la práctica los preceptos morales, concuerdan mejor con el anecdotario de los exempla. Como la famosa anécdota de Diógenes y Alejandro Magno, o como la risa de la muchacha tracia ante Tales que asume distintas variantes a lo largo de la historia (Blumenberg 2009), expresa un elogio de la sabiduría práctica que se manifiesta en todos los hombres. De ahí que los tres pasajes dedicados a Roberto se concentren cada uno en una escena particular, y no tengan pretensiones totalizadoras como sí ocurre en las más extensas entradas dedicadas a los grandes filósofos. Y, a pesar de ello, Petrarca reserva un lugar destacado para Roberto dentro de los ejemplos modernos, ya que esa exclusividad es necesaria para que el elogio no pierda efectividad. El choque entre esas dos tendencias abre un escenario que Petrarca desarrollará luego, sobre todo en el Secretum, donde el modelo heroico De viris / Africa ya se encuentra explícitamente bajo cuestión. Es notable que una de las últimas intervenciones de Agustín en el diálogo haga referencia a la sabiduría del «quotidianus sermo», es decir, aquella que se presenta y se elogia a lo largo de los Mem, opuesta al afán de gloria y amor de Francesco.

\section{Conclusiones}

Así pues, es posible mencionar algunos aspectos importantes de la obra: en primer lugar, representa una búsqueda por parte del autor de un género mediano, que permita la inclusión de un personaje moderno. En segundo lugar, ello se combina con un tipo de ejemplaridad también mencionada en el prólogo al De viris, que no busca modelos intachables de virtud. En tercer lugar, el modelo enciclopédico de varias entradas por personaje tiene como objetivo lograr un retrato dinámico de algunos de ellos, en los que se combina la afición por las letras y la actividad mundana. En el De vita solitaria se propone también un ideal intermedio entre otium y negotium, pero no ya a partir del retrato dinámico, sino a través de la diversidad de personajes que incluye. Y en cuarto lugar, la obra presenta una tensión entre singularidad y multiplicidad que se hace patente en el uso de la biografía y el exemplum. La centralidad de la figura de Roberto no permite que esa tensión se resuelva, así como tampoco se resuelve en el Secretum.

\section{Referencias bibliográficas}

Baldassari, Gabriele (2006): Unum in locum: strategie macrotestuali nel Petrarca politico, Milano, Edizioni Universitarie di Lettere, Economia, Diritto. 
Blumenberg, Hans (2009): La risa de la muchacha tracia: una protohistoria de la teoría, Valencia, Pre-Textos.

Boni, Marco (1949): «Note ai Rerum memorandarum libri», Studi petrarcheschi, II, pp. 167-181.

Breisach, Ernst (2008): Historiography: Ancient, Medieval and Modern, Chicago, University of Chicago Press.

Burke, Peter (2013) «Del Renacimiento a la Ilustración», en Jaume Aurell, Catalina Balmaceda, Peter Burke, Felipe Soza (eds.), Comprender el pasado. Una historia de la escritura y el pensamiento histórico, Madrid, Akal, pp. 143-182.

Burke, Peter (2016): El sentido del pasado en el Renacimiento, Madrid, Akal.

Cascón Dorado, Antonio (1987): «Fenómenos comunes en la transmisión del exemplum y la fábula», Habis, 18-19, pp. 173-186.

Cherchi, Paolo (2002): «Petrarca, Valerio Massimo e "Le concordanze delle storie"», Rinascimento, 42, pp. 31-65.

Cherchi, Paolo (2012): «The unforgettable books of things to be remembered» en Victoria Kirkham, Armando Maggi (eds.), Petrarch: a critical guide to the complete works, Chicago, University of Chicago Press, pp. 151-162.

Cochrane, Eric (1981): Historians and Historiography in the Italian Renaissance, Chicago, University of Chicago Press.

Delle Donne, Fulvio (2016): «Le fasi redazionali e le concezioni della storia nelle Decadi di Biondo: tra storia particolare e generale, tra antica e moderna Roma», en Angelo Mazzocco, Marc Laureys (eds.), A New Sense of the Past: The Scholarship of Biondo Flavio (1392-1463), Leuven, Leuven University Press, pp. 55-88.

Dotti, Ugo (2004): Vita di Petrarca, Roma/Bari, Laterza.

Erasmo de Rotterdam (1703): «Ciceronianus», Opera Omnia, tomo 1, Leiden, Petri Van Der Aa, pp. 974-1026.

Gazzola, Giuseppe (2005) «Petrarch's guide to the Holy Land. Itinerary to the sepulcher of our Lord Jesus Christ», MLN, 120/1, pp. 239-247.

Grafton, Anthony (2011): «El lector humanista», en Guglielmo Cavallo, Roger Chartier (eds.), Historia de la lectura, Buenos Aires, Taurus, pp. 281-328.

Greene, Thomas (1982): The Light in Troy: Imitation and Discovery in Renaissance Poetry, New Haven, Yale University Press.

Guenée, Bernard (1980): Histoire et culture historique dans l'Occident médiéval, Paris, Aubier-Montaigne.

Hankins, James (2000): «Rhetoric, history and ideology: the civic panegyrics of Leonardo Bruni», en James Hankins (ed.), Renaissance Civic Humanism. Reappraisals and Reflections, Cambridge, Cambridge University Press, pp. 143-178.

Ianziti, Gary (2012): Writing history in Renaissance Italy: Leonardo Bruni and the Uses of the Past, Cambridge (Massachusetts), Harvard University Press.

Kelley, Donald R. (1970): The Foundations of Modern Historical Scholarship, Nueva York, Columbia University Press.

Kelly, Samanta (2003): The New Solomon. Robert of Naples (1309-1343) and Fourteenth-Century Kingship, Leiden, Boston, Brill.

Kempshall, Mattew (2011): Rhetoric and the Writing of History, Manchester, Manchester University Press.

Kohl, Benjamin G. (1974): «Petrarch's prefaces to De Viris Illustribus», History and Theory, 13/2, pp. 132-144.

Lyons, John D. (1989): Exemplum: The Rhetoric of Example in Early Modern France and Italy, Princeton, Princeton University Press. 
Mommsen, Theodor (1942): «Petrarch's conception of the 'Dark ages'», Speculum. Journal of Mediaeval Studies, XVII, pp. 226-242.

Nenadic, Rozana / Pozzi, Martín (2014): «Combinaciones genéricas: entre lo didáctico y lo epidíctico», en Alicia Schniebs (ed.), Valerio Máximo. Facta et dicta memorabilia. Hechos y dichos memorables, Buenos Aires, Editorial de la Facultad de Filosofía y Letras, Universidad de Buenos Aires, pp. 53-61.

Nolhac, Pierre (1907): Pétrarque et l'humanisme, Paris, Librairie Honore Champion.

Olson, Kristina M. (1983): «Concivis meus: Petrarch's Rerum memorandarum libri 2.60, Boccaccio's Dec. 6.9, and the specter of Dino del Garbo», Annali D'Italianistica, 22, pp. 375-380.

Pade, Marianne (2014): «The reception of Plutarch from Antiquity to the Italian Renaissance», en Mark Beck (ed.), A Companion to Plutarch, Chichester / West Sussex, Wiley Blackwell, pp. 531-543.

Petoletti, Marco (2014): «Introduzione», in Francesco Petrarca, Rerum memorandarum libri, Firenze, Le Lettere, pp. 7-21.

Petrarca, Francesco (1955a): «De viris illustribus», Pier Giorgio Ricci, Guido Martellotti (eds.), Prose, Milano / Napoli, R. Ricciardi, pp. 217-269.

Petrarca, Francesco (1955b) «De vita solitaria», Pier Giorgio Ricci, Guido Martellotti (eds.), Prose, Milano / Napoli, R. Ricciardi, pp. 285-591.

Petrarca, Francesco (1997): Itinerarium ad sepulcrum Domini, Roma, Lexis Progetti Editoriali. Petrarca, Francesco (2011): Mi secreto. Epístolas, Madrid, Cátedra.

Petrarca, Francesco (2014): Rerum memorandarum libri, ed. de Marco Petoletti, Firenze, Le Lettere.

Pritchard, Telfryn (1993): «The "Ambrose" text of Alexander and the Brahmans», Classica et Medicevalia, 44, pp. 109-139.

Rigolot, François (1998): «The Renaissance crisis of exemplarity», Journal of the History of Ideas, 59/4, pp. 557-563.

Salutati, Coluccio (1891): Epistolario, ed. de Francesco Novati, Tomo 1, Roma, Forzani E. C. Tipografi del Senato.

Sarnelli, Mauro (2003): «Tipologie biografiche dall'Alto Medioevo al primo Trecento», en Mauro Sarnelli, Biografia: genesi e strutture, Roma, Aracne, pp. 11-78.

Ullman, Berthold L. (1923): «Petrarch's favorite books», Transactions and Proceeding of the American Philological Association, LIV, pp. 21-38.

Ullman, Berthold L. (1946 [1955]): «The composition of Petrarch's De vita solitaria and the history of the Vatican manuscript», en Berthold L. Ullman, Studies in the Italian Renaissance, Roma, Edizioni di Storia e Letteratura, pp.135-175.

Vickers, Brian (1983): «Epideictic and epic in the Renaissance», New Literary History, 14/3, pp. 497-537.

Wilcox, Donald (1969): The Development of Florentine Humanist Historiography in the Fifteenth Century, Cambridge (Massachusetts), Harvard University Press.

Woolf, Daniel (2012): The Oxford History of Historical writing, Oxford, Oxford University Press.

Zaccaria, Vittorio (2001): Boccaccio narratore, storico, moralista e mitografico, Firenze, Olschki Editore. 